\title{
Study of Milling of Low Thickness Thermoplastic Carbon Fiber Composites in Function of Tool Geometry and Cutting Conditions
}

\author{
Alejandro Sambruno ( $\square$ alejandro.sambruno@uca.es ) \\ Universidad de Cadiz https://orcid.org/0000-0002-6663-2962
}

\section{Fermin Bañon}

Faculty of Engineering, Mechanical Engineering and Industrial Design Department, University of Cadiz, Av. Universidad de Cadiz 10, E-11519 Puerto Real, Cadiz, Spain

\section{Jorge Salguero}

Faculty of Engineering, Mechanical Engineering and Industrial Design Department, University of Cadiz, Av. Universidad de Cadiz 10, E-11519 Puerto Real, Cadiz, Spain

\section{Bartolome Simonet}

Nanotures SL, C. Inteligencia 19, Tecnoparque Agroalimentario, E-11591 Jerez de la Frontera, Cadiz, Spain

\section{Moises Batista}

Faculty of Engineering, Mechanical Engineering and Industrial Design Department, University of Cadiz, Av. Universidad de Cadiz 10, E-11519 Puerto Real, Cadiz, Spain

\section{Research Article}

Keywords: Milling, CFRTP, Surface Quality, Rz, Fiber pull-out, C/TPU

Posted Date: March 22nd, 2021

DOl: https://doi.org/10.21203/rs.3.rs-313664/v1

License: (c) (i) This work is licensed under a Creative Commons Attribution 4.0 International License. Read Full License

Version of Record: A version of this preprint was published at The International Journal of Advanced Manufacturing Technology on April 10th, 2021. See the published version at https://doi.org/10.1007/s00170-021-07050-1. 


\section{Abstract}

The application of Carbon Fiber Reinforced ThermoPlastic matrix composites (CFRTP) is constantly increasing in various industrial sectors. Their mechanical properties and advantages compared to thermoset composite materials make them very important materials. Nevertheless, CFRTP machining generates a current problem due to the anisotropy of these materials, the difficulty of impregnation of the reinforcement in the matrix and its low melting temperature. For this reason, the study of conventional operations such as milling to achieve geometries with a good surface quality and reduced cosmetic defects is a line of research of great interest. In this article, a comparison of five cutting tools with different geometries has been made in CFRTP milling. The surface quality and the formation of visual defects such as fiber pull-out have been evaluated for each tool and combination of cutting parameters. In this sense, $16.42 \mu \mathrm{m}$ in terms of Rz is the minimum average value for the complete experiment obtained for a conventional tool (Tool A). However, surface qualities in terms of Rz close to $20 \mu \mathrm{m}$ and minimum cosmetic defects have been obtained with a hybrid tool (Tool C) with $-10^{\circ}$ helix angle and 8 teeth with a combination of cutting parameters of $0.07 \mathrm{~mm} /$ tooth and $3000 \mathrm{rpm}$, being the most complete tool of the experiment.

\section{Introduction}

The advantages and applications of thermoset matrix composite materials in various sectors are well known, especially in the aeronautical sector [1-3].

Alongside these materials, the use of composite materials reinforced with carbon fiber and thermoplastic matrix (CFRTP) is beginning to generate interest [4]. These maintain the excellent weight to mechanical properties ratio of thermosets. In addition, they can achieve higher impact resistance and faster processing times $[5,6]$.

These characteristics make them strategic materials in various sectors, especially in the automotive industry, due to the fact that they are materials that can be manufactured in mass [7]. Sectors such as the sports and marine industries are also beginning to apply these materials to various components [8]. In addition, this composite is stacked with metal alloys such as steel, in order to improve their functional performance [9].

Nevertheless, in order to achieve their purpose, these materials must be machined to adopt a specific geometry in the shortest possible production time to reduce costs [4].

Due to the abrasive nature of the reinforcement and the low cohesion between filaments and matrix due to the low viscosity of the thermoplastic material can generate great difficulties in the machining of these materials [10].

Also, the characteristic anisotropy of these materials means that each orientation of the material behaves differently when using cutting geometries, which can lead to defects such as delamination or low surface 
quality [11]. This in combination with the temperatures generated in the machining of these materials makes it necessary to study in detail machining operations that can correctly machine these materials [12].

An operation widely used in the machining of composite materials and of great interest is milling $[13,14]$. It is a fast and flexible operation, which allows the reduction of operation times and the possibility of using many cutting geometries according to the needs, even machining several materials in the form of a stack at the same time $[15,16]$.

However, due to the characteristics of CFRTPs, the milling of these materials can generate a poor surface finish due to possible losses of thermoplastic matrix or that the cutting edges do not completely cut the filaments depending on the cutting orientation [4]. Turki et al. [17] have studied the mechanisms that control the drilling of carbon and epoxy composites using orthogonal cutting. The results of their paper indicate that the orientation of carbon fibers plays an important role in the machining results and the mechanisms of shearing, bending and matrix detachment. Furthermore, the correct selection of parameters has a direct influence on the surface quality obtained, resulting in scrapped parts [11].

For this reason, the search for specific cutting geometries for thermoset and thermoplastic composites is a line of great interest in current research. A comparison of tools for CFRTP milling was made by Masek et al. [18] in which they modified the feed rate per tooth, the cutting speed and the machining depth. In their study, they indicate the need to use cutting tools with positive inclination angles in combination with a compression helix to obtain the best results. This is in line with the results obtained for Voss et al. [11] in milling CFRPs, where positive rake angles allow easier chip evacuation producing smoother surfaces. Xu et al. [19] in their article point out how the machining of CFRP in the form of drilling produces thermal and mechanical damage to the machined wall surfaces in the form of delamination of the interface, cracks, cavities and chip adhesion.

On the other hand, there is a direct relationship between the surface quality obtained and the parameters established in the machining of composite materials. The increase in feed rate produces an increase in the cutting forces which indicates greater abrasive wear on the cutting edges [20]. This, depending on the orientation of the carbon fibers and the cutting geometry, reduces the cutting capacity of the tools producing rougher surfaces and an increase in delaminations [11].

In milling, high cutting speed values increase the cutting capacity of the cutting edges allowing the cutting geometries to minimize delaminations that occur at angles of $135^{\circ}$ and $45^{\circ}[21,22]$.

Nevertheless, there seems to be little information about the influence of cutting parameters and the selection of suitable cutting geometries for the milling of thermoplastic composites. The anisotropy of these materials and the possible loss of matrix due to the temperatures reached as a function of the established parameters can generate a poor surface quality. Xu et al. [23] in their article specify how a decrease in cutting speed implies a lower process temperature, resulting in more consistent machining. In 
addition, Xu et al. [24] in other research suggest that low feed rates for machining polymer composites with thermoset resin mean lower process temperature and lower internal delaminations.

Another factor to take into account in machining processes such as milling is the effect of temperature on the matrix used in the composite. Xu et al. [25] explain how the thermoplastic resin used in their machining (PEEK) has a high degree of ductility and tends to deform plastically during the process, as the machining temperature exceeds the glass transition temperature of the material. In addition, Khanna et al. [26] in their article specify how the inclusion of cryogenic cooling in the machining of CFRP can lower the temperature and thus lead to better results. In this sense, Khanna et al. obtain better surface qualities as well as a lower number of delaminations on the surface of the material.

For these reasons, this article proposes a parametric and comparative study of five cutting tools of different geometry. For this purpose, for each tool the feed rate per tooth and the cutting speed will be modified in order to establish a relationship between the surface quality in terms of Rz, the cutting parameters and the selected geometry. Finally, the most suitable cutting geometry will be identified, as well as the range of cutting parameters that optimize the surface quality in the machining of thermoplastic composite materials.

\section{Materials And Methods}

To carry out the experiments, carbon fiber has been used as a reinforcement and thermoplastic resin as a matrix to make the CFRTP composite. The composite material has been manufactured to achieve a final thickness of $2.08 \mathrm{~mm}$. Table 1 shows the main characteristics of the material, as well as, some interesting properties of the reinforcement and the matrix, respectively.

For the development of this research, different tool geometries have been considered according to the material to be machined, its thickness and the cutting conditions. In addition, these tools have been recommended by the manufacturer for machining thermoplastic composites.

In this way, five tools of $6 \mathrm{~mm}$ diameter each with different number of teeth have been used to evaluate the effect of cutting geometry on the tests performed. Table 2 shows the main characteristics of each of the tools used. For convenience, and in order to identify them more easily, they have been designated with the letters A-E. In addition, images of the tools will be placed throughout the manuscript to make the reading easier. Figure 1 shows a macrograph of each tool together with its designation. 
Table 1

Fiber, matrix and CFRTP characteristics.

\begin{tabular}{|lll|}
\hline Reinforcement & Fiber type & Twill $200 \mathrm{~g} / \mathrm{m}^{2}$ \\
\cline { 2 - 3 } Matrix & Fiber thickness & $0.25 \mathrm{~mm}$ \\
\hline \multirow{2}{*}{ CFRTP } & Resin type & TPU (Polyurethane) \\
\cline { 2 - 3 } & Melting Temperature & $145^{\circ} \mathrm{C}$ \\
\cline { 2 - 3 } & Ply Orientation & {$\left[0^{\circ} / 90^{\circ}\right] \mathrm{s}$} \\
\hline Number of plies & 7 \\
\hline Composite thickness (t) & $2.08 \mathrm{~mm}$ \\
\cline { 2 - 3 } & Fiber / Matrix (\%) & $74.2 / 25.8$ \\
\cline { 2 - 3 } & Tensile strength (Mpa) & 754 \\
\cline { 2 - 3 } & Young Modulus (Gpa) & 23.4 \\
ILSS (Mpa) & 8.1 \\
\hline
\end{tabular}

Table 2. Properties of tools employed in this experiment.

\begin{tabular}{|c|c|c|c|c|c|}
\hline Designation & Material & Diameter & $\mathrm{N}^{\circ}$ of teeth $(z)$ & & eometry \\
\hline A & $\begin{array}{l}\text { Tungsten Carbide Cobalt } \\
\text { (WC-Co), non-coated }\end{array}$ & $6 \mathrm{~mm}$ & 2 & $\begin{array}{l}\text { Helix } \\
\text { angle } 30^{\circ}\end{array}$ & \\
\hline B & $\begin{array}{l}\text { Tungsten Carbide Cobalt } \\
\text { (WC-Co), non-coated }\end{array}$ & $6 \mathrm{~mm}$ & 11 & - & \\
\hline $\mathrm{C}$ & $\begin{array}{l}\text { Tungsten Carbide Cobalt } \\
\text { (WC-Co), diamond coated }\end{array}$ & $6 \mathrm{~mm}$ & 8 & $\begin{array}{c}\text { Helix } \\
\text { angle }-10^{\circ}\end{array}$ & \\
\hline D & $\begin{array}{l}\text { Tungsten Carbide Cobalt } \\
\text { (WC-Co), diamond coated }\end{array}$ & $6 \mathrm{~mm}$ & 8 & $\begin{array}{l}\text { Helix } \\
\text { angle } 0^{\circ}\end{array}$ & \\
\hline E & $\begin{array}{l}\text { Tungsten Carbide Cobalt } \\
\text { (WC-Co), diamond coated }\end{array}$ & $6 \mathrm{~mm}$ & 8 & $\begin{array}{l}\text { Helix } \\
\text { angle } 10^{\circ}\end{array}$ & \\
\hline
\end{tabular}

A 5-axis CNC machine (Kondia Five 400, Elgoibar, Guipúzcoa, Spain) has been used to perform the tests. In this experiment it has been necessary to use only 3 of the 5 axes of the machine: $X, Y$ and $Z$ axis. Three spindle speeds ( $\mathrm{S}, \mathrm{rpm}$ ) and two feed rates per tooth ( $\mathrm{fz}, \mathrm{mm} /$ tooth) have been combined to obtain a combination of six trials. The set values for the cutting parameters have been defined on the basis of 
other studies and real application cases, and are indicated in Table 3. Each test is performed in the absence of lubricant due to the improved cutting conditions of composites.

Table 3

Combination of cutting parameters

used for each test.

\begin{tabular}{|lll|}
\hline Trial & S (rpm) & Fz (mm/tooth) \\
\hline 1 & 1000 & 0.03 \\
\hline 2 & 1000 & 0.05 \\
\hline 3 & 1000 & 0.07 \\
\hline 4 & 3000 & 0.03 \\
\hline 5 & 3000 & 0.05 \\
\hline 6 & 3000 & 0.07 \\
\hline
\end{tabular}

Each trial will have a machining length of 50 millimeters. On the other hand, only the central $30 \mathrm{~mm}$ will be analyzed, in order to eliminate the input and output of tool in composite. To ensure a homogeneous cut each tool is placed 3 millimeters below the lower face of material. A clamp applies pressure to the material to keep it fixed, leaving a gap of $10 \mathrm{~mm}$ between sides (Fig. 2).

After machining the slots, a rugosimeter (Mahr Perthometer, PGK 120, Göttingen, Germany) has been used to measure the final surface quality. For this purpose, the average of the absolute values of the five highest peaks and the five lowest valleys has been measured in terms of Rz. The measurements have been taken on both sides of the slot, i.e. in the direction of machining, up milling (left side of slot, in accordance of cutting direction) and against, down milling (right side of slot, in opposition of cutting direction). In order to verify the values calculated, 6 measurements have been taken on each side of the slot at different points on its surface (Fig. 3).

A typical defect in the machining of composite materials is the generation of fiber pull-out. In this article it has been carried out an analysis of the fiber pull-out generated in the cuts according to each tool. For this purpose, a stereoscopical microscope (Nikon, SMZ 800, Tokyo, Japan) has been employed in order to obtain macrographies of the sections where a major fiber pull-out appears.

\section{Results}

\subsection{Machining strategy analysis}

Table 4 shows the average values of Rz together with their deviations. It can be seen how the Rz values obtained for up-milling and down-milling appear in different columns. In general, it can be noted that the values achieved with down-milling strategy are much higher than those of up-milling. This makes sense because in opposition there is a minor force when the tool tooth hits the material. This phenomenon in 
metal alloys can be favorable, but for composites a lower cutting force can cause the fibers to deform but not break. This may result in a lower final surface quality obtained during machining, which is reflected in values of the table (Fig. 4.a.). These results are consistent with other studies, such as Nguyen et al. [27] and Ozkan et al. [28] in which they note a better machining in CFRP following the up milling strategy. In addition, the fiber pull-out defect appears to a greater extent on the right side of the slot, i.e. with the down milling strategy (Fig. 4.b).

For example, in tool type A, values between 16.42 and $26.00 \mu \mathrm{m}$ appear in up milling. On the other hand, the $\mathrm{Rz}$ reaches values of up to $57.11 \mathrm{um}$. The deterioration of the surface quality becomes double if the two machining strategies are compared. The same phenomenon occurs with the rest of the tools used in this experiment. Therefore, it seems that for the performance of CFRTP contourmilling maintaining an upmilling strategy provides a higher surface quality.

The highest $R z$ value is generated by tool $B$ in $1000 \mathrm{rpm}$ and $0.05 \mathrm{~mm} /$ tooth test being $115.14 \mu \mathrm{m}$. Tool $\mathrm{D}$ also produces a very high value of $103.44 \mathrm{um}$ at $1000 \mathrm{rpm}$ and $0.03 \mathrm{~mm} /$ tooth. The best surface quality is given to tool $A$ with values such as $16.42-16.57 \mathrm{um}$. This article focuses on getting good surface quality in conventional CFRTP machining. Therefore, after the previous discussion it has been decided to analyze in detail only the Rz values that are in accordance of machining (up-milling), since, they are the smallest. 
Table 4

Rz values obtained in all tests.

\begin{tabular}{|c|c|c|c|c|c|}
\hline Tool & Test & $\begin{array}{l}\text { Spindle } \\
\text { speed } \\
S[\text { rpm] }\end{array}$ & $\begin{array}{l}\text { Feed rate } \\
\text { per tooth } \\
\text { Fz [mm/tooth] }\end{array}$ & $\begin{array}{l}\text { Average Rz }{ }^{1} \\
\text { (Up-milling) } \\
{[\mu \mathrm{m} \pm \mu \mathrm{m}]}\end{array}$ & $\begin{array}{l}\text { Average Rz }{ }^{1} \\
\text { (Down-milling) } \\
{[\mu \mathrm{m} \pm \mu \mathrm{m}]}\end{array}$ \\
\hline \multirow[t]{6}{*}{$A$} & 1 & 1000 & 0.03 & $17.71 \pm 4.10$ & $45.31 \pm 23.70$ \\
\hline & 2 & 1000 & 0.05 & $24.53 \pm 3.85$ & $51.38 \pm 21.25$ \\
\hline & 3 & 1000 & 0.07 & $16.57 \pm 4.71$ & $33.51 \pm 16.15$ \\
\hline & 4 & 3000 & 0.03 & $16.42 \pm 6.52$ & $57.11 \pm 38.54$ \\
\hline & 5 & 3000 & 0.05 & $26.00 \pm 8.21$ & $46.59 \pm 16.64$ \\
\hline & 6 & 3000 & 0.07 & $16.54 \pm 6.55$ & $32.10 \pm 4.62$ \\
\hline \multirow[t]{6}{*}{ B } & 1 & 1000 & 0.03 & $24.91 \pm 4.26$ & $77.74 \pm 31.10$ \\
\hline & 2 & 1000 & 0.05 & $58.32 \pm 12.02$ & $115.14 \pm 29.08$ \\
\hline & 3 & 1000 & 0.07 & $19.82 \pm 2.77$ & $35.36 \pm 12.65$ \\
\hline & 4 & 3000 & 0.03 & $22.00 \pm 5.35$ & $31.88 \pm 25.80$ \\
\hline & 5 & 3000 & 0.05 & $35.54 \pm 6.85$ & $42.69 \pm 11.73$ \\
\hline & 6 & 3000 & 0.07 & $54.78 \pm 8.98$ & $30.03 \pm 6.65$ \\
\hline \multirow[t]{6}{*}{ C } & 1 & 1000 & 0.03 & $36.53 \pm 17.53$ & $59.90 \pm 13.09$ \\
\hline & 2 & 1000 & 0.05 & $30.24 \pm 8.89$ & $58.12 \pm 18.65$ \\
\hline & 3 & 1000 & 0.07 & $23.72 \pm 9.69$ & $49.25 \pm 28.37$ \\
\hline & 4 & 3000 & 0.03 & $40.91 \pm 13.98$ & $27.29 \pm 6.96$ \\
\hline & 5 & 3000 & 0.05 & $31.12 \pm 9.22$ & $36.34 \pm 10.53$ \\
\hline & 6 & 3000 & 0.07 & $24.03 \pm 6.50$ & $24.09 \pm 4.45$ \\
\hline \multirow[t]{6}{*}{ D } & 1 & 1000 & 0.03 & $21.73 \pm 13.30$ & $103.44 \pm 46.53$ \\
\hline & 2 & 1000 & 0.05 & $21.17 \pm 5.62$ & $63.77 \pm 10.69$ \\
\hline & 3 & 1000 & 0.07 & $34.03 \pm 5.48$ & $62.83 \pm 17.54$ \\
\hline & 4 & 3000 & 0.03 & $37.29 \pm 5.84$ & $53.71 \pm 18.39$ \\
\hline & 5 & 3000 & 0.05 & $44.44 \pm 7.92$ & $62.62 \pm 14.52$ \\
\hline & 6 & 3000 & 0.07 & $47.53 \pm 14.61$ & $54.23 \pm 21.08$ \\
\hline$E$ & 1 & 1000 & 0.03 & $28.25 \pm 17.18$ & $66.03 \pm 18.84$ \\
\hline
\end{tabular}




\begin{tabular}{|clllll|}
\hline Tool & Test & $\begin{array}{l}\text { Spindle } \\
\text { speed } \\
S[\mathrm{rpm}]\end{array}$ & $\begin{array}{l}\text { Feed rate } \\
\text { per tooth } \\
F z[\mathrm{~mm} / \text { tooth }]\end{array}$ & $\begin{array}{l}\text { Average Rz }^{1} \\
\text { (Up-milling) } \\
{[\mu \mathrm{m} \pm \mu \mathrm{m}]}\end{array}$ & $\begin{array}{l}\text { Average Rz }^{1} \\
\text { (Down-milling) } \\
{[\mu \mathrm{m} \pm \mu \mathrm{m}]}\end{array}$ \\
\hline 2 & 1000 & 0.05 & $25.26 \pm 8.71$ & $62.38 \pm 13.43$ \\
\hline 3 & 1000 & 0.07 & $39.20 \pm 10.87$ & $82.89 \pm 15.53$ \\
\hline 4 & 3000 & 0.03 & $35.64 \pm 18.09$ & $53.52 \pm 13.18$ \\
\hline 5 & 3000 & 0.05 & $31.83 \pm 6.21$ & $37.15 \pm 7.96$ \\
\hline 6 & 3000 & 0.07 & $38.44 \pm 6.85$ & $54.45 \pm 6.69$
\end{tabular}

${ }^{1}$ Average values are based on 6 different measurements.

\subsection{An overview of Rz values measured}

Figure 5 shows the Rz values for machining the thermoplastic composite following the up-milling strategy. Each color represents the 6 corresponding trials for each tool. The aim of this subsection is to analyze the results obtained and to define a description of the defects in the tools employed.

In this way, it can be seen how, as discussed in previous section, the lower values of Rz are acquired by tool A. This tool has the biggest evacuation channel of all the tools employed. Chip evacuation is one of the most relevant aspects in composite machining. As mentioned in other studies, such as those carried out by Pereira et al. [29] and Wang et al. [30], a smaller chip channel could cause the chip to get stuck in the tool, causing an increase in the cutting forces generated during machining. The CFRTP used in this article has a low glass transition temperature and is therefore quite influenced by the temperature caused by the machining process. The matrix of composite melts and joins the carbon fiber particles that are removed during machining. This means that the chip generated needs enough space to be evacuated and does not interfere in the final surface quality of composite.

Tools C, D and E, have 8 teeth arranged along the diameter, therefore they have a smaller evacuation channel than tool A. This makes it difficult to remove the chips, which can get stuck in the tool itself. Figure 6 shows the chip stuck in the tool channel at the end of one of the tests. For this reason, these three tools take a higher Rz value than tool A. Tool B is the most particular of 5 tools employed. It contains 11 teeth distributed in a helical way along the tool diameter. This means that the evacuation channels generated between teeth are very small. This is the reason for the randomness of results shown in Fig. 4. Some of the Rz values obtained with tool B are similar to those obtained with the other 4. However, two of them are the highest values of the experimental set.

\subsection{Analysis of the surface quality obtained per tool}

In this subsection the analysis of the surface quality obtained for each trial is developed. In each graph, the average Rz values together with their deviations are represented. For each combination of parameters, 
a macrograph of the fiber pull-out generated in that trial has also been included. Above the set of macrographies there are two yellow dashed lines that indicate the point from which the fiber pull-out is generated and the upper limit of this defect.

Figure 7 shows the values obtained for tool A. It can be seen how the highest points of Rz occur with 0.05 $\mathrm{mm} /$ tooth for both cutting speeds. In addition, the deviations generated for $1000 \mathrm{rpm}$ are smaller than those for $3000 \mathrm{rpm}$. Higher cutting speed means higher temperature during the machining process [31]. The temperature causes the adhesion defect to increase, making both the tool and the material susceptible to this defect. This may justify a wider range of values for a cutting speed of $3000 \mathrm{rpm}$. However, it should be noted that tool $A$ is the one that has obtained the best results from Rz. In particular, a cutting speed of $3000 \mathrm{rpm}$ and a feed rate of 0.03 and $0.07 \mathrm{~mm} /$ tooth generate values of 16.42 and $16.54 \mu \mathrm{m}$, respectively.

On the other hand, it can be seen that the geometry of tool A is not optimal for achieving a good cosmetic finish. The fiber pull-out defect appears in all the combinations of parameters used, being $1.58 \mathrm{~mm}$ the highest value obtained. The top layer of carbon fiber in composite is deformed in the direction of tool rotation but does not break. This tool is not completely designed for machining composite materials. The number of teeth of a tool for composite machining is one of the most influential variables in the process.

Hintze W. et al. [32] in their study agree that an increase in the number of teeth generates poorer results in terms of surface quality, but can improve the pull-out defect or delaminations of composite materials. This discussion matches the results obtained in this experiment. As seen above, tool $A$ is the one that shows the lowest values of Rz.

As mentioned above, tool $\mathrm{B}$ has 11 cutting edges distributed in a helical pattern along the tool diameter. This tool geometry is designed to perform the final finish of a contourmilling process on composite materials. The high number of teeth makes the carbon fibers break more easily. This is reflected in the macrographs shown in Fig. 8. Compared to tool A, the fiber pull-out defect generated is much lower and in some cases is even close to 0 . In contrast, in the combination of $1000 \mathrm{rpm}$ and $0.05 \mathrm{~mm} /$ tooth parameters this defect can be seen significantly. It should be noted that the fiber pull-out coincides with the highest $\mathrm{Rz}$ value obtained in this set of trials.

With such small and even insignificant evacuation channels, tool blockage can occur during machining. Fiber particles next to the temperature affected adhesive could consolidate and get stuck between the tool and the material. This can lead to particle adhesion on the machined surface and even to the tool losing its cutting ability.

However, very striking Rz values appear when machining CFRTP with this type of tool. In particular, there are several combinations of parameters that achieve average values between 19.82-24.91 $\mu \mathrm{m}$ with small deviations, similar to those obtained by tool A. On the other hand, this tool contains the highest values of $\mathrm{Rz}$, reaching $70.34 \mu \mathrm{m}$. Authors such as Geier N. et al. [22] obtain similar results. With this tool geometry they achieve higher Rz values compared to other tool types. 
Tools C, D and E are a hybrid between type A and B. A greater number of cutting edges is known to benefit the machining of composite materials. For this reason, these tools have 8 cutting edges. In addition, an evacuation channel is a positive element that allows the chip not to affect the final machined surface.

Figure 9.a shows the values measured for tool $\mathrm{C}$ with a $-10^{\circ}$ helix angle. It can be seen that for the same cutting speed, Rz values decrease as the feed rate increases. In the same way, the deviations shown follow the same trend as the average values, i.e. they become smaller as feed rate increases. This causes that the final quality obtained is more homogeneous with a greater removal of material.

In general, tool D (Fig. 9.b) and tool E (Fig. 9.c) show similar trends.

There is a higher accuracy of the measured values as the feed rate increases. In addition, in all 3 tools, as the cutting speed increases, the Rz values increase. This effect also occurs with the previous tools. An increase in the cutting speed implies an increase in the process temperature, which can lead to a less clean cut due to the adhesion defect.

The 3 tools are in a similar range of average values. However, it is worth noting the results obtained for tool D (Fig. 9.b) with a combination of $1000 \mathrm{rpm}$ and $0.07 \mathrm{~mm} /$ tooth. This combination is the one that generates a lower average value together with a small deviation. The negative helix angle produces the highest Rz values. However, the Rz values obtained for a positive helix angle are smaller. In an up-milling strategy, a positive helix angle makes the cutting edge of the tool to machine in the same direction as the helix angle, which could result in better material removal.

On the other hand, tool $C$, with a negative helix angle $\left(-10^{\circ}\right)$ generates a decreasing trend as the feed rate increases. On the contrary, the trend in tool $\mathrm{E}$ (positive helix angle, $10^{\circ}$ ) increases as the feed rate also increases.

As regards the fiber pull-out defect, it can be seen how, in general, the high number of cutting edges performs its function. This defect appears in a minor way in the tools that have a helix angle: $\mathrm{C}$ and $\mathrm{E}$. In tool $\mathrm{C}$ an increase in cutting speed leads to a decrease in carbon fiber pull-out. As for tool $\mathrm{E}$, it can be seen that at low feed rates the results obtained are the best of the set of trials carried out. On the other hand, from a feed rate of $0.07 \mathrm{~mm} /$ tooth, it seems that the geometry of the tool makes it difficult to cut these wires.

Tool D, with a helix angle of $0^{\circ}$, has generated fiber pull-out defect in all trials. The helix angle of a tool gives the chip channel a curved shape, in which the detached chips can be evacuated easier. In this case, as could be seen in Fig. 6 , the absence of a helix angle has made chip removal difficult during machining. This has caused a blockage of the tool with fiber particles consolidated to the composite matrix.

Shengchao H. et al. [33] study the wear of this type of tools in CFRP machining. They conclude that using this type of tool decreases the cutting force required in the process. Lower cutting force allows higher surface qualities to be achieved. In this article, tool $D$ generates a surface quality similar to the one 
obtained by tool A when machining at low feed rates. However, tool E, with a positive helix angle $\left(+10^{\circ}\right)$ generates less fiber pull-out when the composite is machined at low feed rates.

\subsection{Discussion of CFRTP milling}

The milling of thermoplastic matrix compounds with different types of tool geometries has led to significant results. In terms of surface quality, the conventional tool with 2 teeth (Tool A), has generated the lowest Rz values obtained in this experiment. Tool $B$ has produced quite different results. It should be noted that this tool geometry is designed to perform the surface finishing of previously machined materials. Therefore, when a complete slot is made with this kind of tool, there may be an unpredictable behavior. Tools C, D and E show slightly higher Rz values than those caused by the conventional tool (A). However, these values have a fairly clear trend.

As for the fiber pull-out defect, it is observed that the conventional tool (A), obtains the worst results. In all the tests carried out with tool $A$, this defect has been generated in a homogeneous way. As it has been commented along the document, this tool is not designed to perform the machining of composite materials. Therefore, although it generates good surface qualities, it is not able to eliminate the fibers that are found in the upper layer of the material. Something similar has happened with tool D, however, the defect in this tool is caused by the absence of a helix angle. Tool B has generally offered the best results in terms of fiber pull-out. The height of the loose fibers found in the material is very close to 0 . Tool $\mathrm{C}$, with a negative helix angle $\left(-10^{\circ}\right)$ provides better results when machining the CFRTP at a high cutting speed. By contrast, tool $\mathrm{E}$, with a positive helix angle $\left(+10^{\circ}\right)$, has been affected by the feed rate.

In general, CFRTP milling results in a variety of defects. The use of a thermoplastic matrix makes the glass transition temperature of the material lower than that of a thermosetting resin. Therefore, the thermoplastic material can be more affected by the temperature of the milling process than the CFRP. This is reflected in the surface quality obtained in other experimental studies where the Rz values are much lower than those obtained in this experiment [34]. On the other hand, as in the case of CFRP [35, 36], the milling of this type of material produces defects such as the elimination of the fiber yarns due to the efforts made by the cutting tool.

The machining of this type of material in other non-conventional technologies such as abrasive water jet machining, AWJM, could be interesting in terms of surface quality. In general, the temperature generated in the AWJM is lower than that caused by conventional milling [37]. This can cause the thermoplastic matrix of a composite material to be less affected by machining. However, the selection of an appropriate cutting tool geometry can achieve really good cosmetic defects that the waterjet may not get. Today, cutting tools are manufactured such as B, C, D and E tools, designed to eliminate defects such as fiber pull-out, internal delaminations or die loss during machining.

\section{Conclusions}


An experimental study on the influence of tool geometry and cutting conditions on the milling of thermoplastic carbon fiber composites has been carried out. The machining has been discussed by means of the surface quality obtained in material in terms of Rz and the cosmetic quality of material in terms of fiber pull-out. The literature review allowed to select cutting speed and feed rate as the most influential input parameters in the machining performed, keeping other parameters fixed, such as the machining depth at $3 \mathrm{~mm}$. Cutting speeds have been 1000 and $3000 \mathrm{rpm}$, moreover feed rates per tooth have been $0.03,0.05,0.07 \mathrm{~mm} /$ tooth.

Three different types of tools, each with $6 \mathrm{~mm}$ diameter, have been selected for milling. Tool A has a conventional milling geometry with two cutting edges and a wide evacuation channel. Tool $B$ has a tool geometry designed for finishing composite materials. It contains 11 teeth arranged helically along the flute. Tools C, D and E have 8 cutting edges with teeth distributed along the surface. As there are more cutting edges, the chip channel of this tool is narrower than that of tool A. Each of them has a specific helix angle: $C\left(-10^{\circ}\right), D\left(0^{\circ}\right), E\left(10^{\circ}\right)$. In order to obtain a repeatability and reproducibility of the measured values, 6 measurements of Rz have been taken on each side of slot at different points on its surface. The most relevant conclusions of this research are as described below:

- The up-milling and down-milling strategies have been analyzed with the 5 tools used in this experiment. It has been seen how the down-milling strategy, in general, always obtains higher Rz values than those resulting from the up-milling strategy. In opposition machining, a lower cutting force is generated when the tool hits the material. In metal alloys this cutting force can generate a better surface quality. On the other hand, in the machining of composites, a low cutting force can cause the fiber yarns to be deformed by the path of the tool but not to break off. This discussion has been contrasted with other studies of milling of thermostable composite materials, where they agree that the down-milling strategy generates a worse surface quality is the machined surface. Since the objective of the article is to find the best results for CFRTP machining with different types of tools, it has been decided to analyze in detail only the Rz values and the fiber pull-out defect achieved for the up-milling strategy.

- CFRTP milling per tool has been analyzed in terms of Rz and fiber pull-out. The conventional tool (A) is the one that has obtained the best results of $\mathrm{Rz}$, being $16.42 \mu \mathrm{m}$ the minimum average value for the complete experiment. Tool B achieves rather low average values of Rz, such as $19.82 \mu \mathrm{m}$, but at the same time gets the highest values of the whole experiment, $58.32 \mu \mathrm{m}$ or $54.78 \mu \mathrm{m}$. Tools C, D and $E$ have a similar range of values, from roughly 21 to $47 \mu \mathrm{m}$. However, they show different trends from each other. Tool $C$ shows a decrease in $R z$ values as the feed rate increases. In tools $D$ and $E$, the $R z$ values increase as the feed rate too.

- It has been discussed how these results can be related to the chip evacuation channel of each tool. A small chip channel can cause the chip to get stuck in the tool, causing an increase in the cutting forces generated during machining. In addition, the low glass transition temperature of the CFRTP used in this experiment may ease tool blockage. Tool A has the largest evacuation channel, so it is less likely to lose its cutting ability. Tools C, D and E have 8 cutting edges, which makes the 
evacuation channels very small compared to tool $A$. Thus, it is understandable that the Rz values obtained for tools $C, D$ and $E$ are higher than for tool A. Tool B has the smallest evacuation channel so it shows the highest $\mathrm{Rz}$ values of the whole experiment.

- An inspection of the fiber pull-out defect produced in the material after machining has been carried out. It has been possible to see how tool A does not have a cutting geometry suitable for machining composites. The fibers are deformed but not broken. This has occurred in all the tests of this tool. Tool C generates the minimum fiber pull-out at cutting speeds of $3000 \mathrm{rpm}$. Tool E, also generates minimum fiber pull-out at low feed rates $0.03-0.05 \mathrm{~mm} /$ tooth.

Finally, the most complete tool geometry for machining thermoplastic composites is the $\mathrm{C}$ tool, with 8 cutting edges and a helix angle of $-10^{\circ}$. This tool at $0.07 \mathrm{~mm} /$ tooth and a cutting speed of $3000 \mathrm{rpm}$ has obtained average Rz values similar to the minimum values achieved by tool A. Furthermore, with this combination of parameters it achieves a minimum fiber pull-out defect.

\section{Declarations}

Author Contributions: A.S. and F.B. developed machining tests. M.B. and J.S. developed data treatment. F.B., A.S., M.B., B.S. and J.S. analyzed the influence of the parameters involved. F.B. and A.S. collaborated in preparing figures and tables and F.B., A.S., M.B., B.S., and J.S. wrote the paper.

Funding: This work has been developed under support of a pre-doctoral industrial fellow financed by NANOTURES SL, mechanical engineering and industrial design department and Vice-rectorate of Transference and Technological Innovation of the University of Cadiz.

Conflicts of Interest: The authors declare no conflict of interest.

Data availability: All the data have been presented in the manuscript.

\section{Nomenclature section}

$R z$-Average of the absolute values of the five highest peaks and the five lowest valleys

TPU- Thermoplastic Polyurethane

C/TPU-Carbon/Thermoplastic Polyurethane

AWJM-Abrasive Water Jet Machining

CFRP-Carbon Fiber Reinforced Plastics with thermoset matrix

CFRTP-Carbon Fiber Reinforced ThermoPlastics

$z$-Number of teeth 
Fz-Feed rate per tooth

S- Spindle Speed

\section{References}

1. Karataş MA, Gökkaya H (2018) A review on machinability of carbon fiber reinforced polymer (CFRP) and glass fiber reinforced polymer (GFRP) composite materials. Def Technol 14:318-326. https://doi.org/10.1016/j.dt.2018.02.001

2. Haddad M, Zitoune R, Bougherara $\mathrm{H}$, et al (2014) Study of trimming damages of CFRP structures in function of the machining processes and their impact on the mechanical behavior. Compos Part $B$ 57:136-143. https://doi.org/10.1016/j.compositesb.2013.09.051

3. Bañon F, Sambruno A, Fernandez-Vidal S, Fernandez-Vidal SR (2019) One-shot drilling analysis of stack CFRP/UNS A92024 bonding by adhesive. Materials (Basel) 12:1-18. https://doi.org/10.3390/ma12010160

4. Masek P, Zeman P, Kolar P, Holesovsky F (2019) Edge trimming of C/PPS plates. Int J Adv Manuf Technol 101:157-170. https://doi.org/10.1007/s00170-018-2857-1

5. Goto K, Imai K, Arai M, Ishikawa T (2019) Shear and tensile joint strengths of carbon fiber-reinforced thermoplastics using ultrasonic welding. Compos Part A Appl Sci Manuf 116:126-137. https://doi.org/10.1016/j.compositesa.2018.10.032

6. Yao S, Jin F, Rhee KY, et al (2018) Recent advances in carbon-fiber-reinforced thermoplastic composites: A review. Compos Part B 142:241-250. https://doi.org/10.1016/j.compositesb.2017.12.007

7. Ishikawa T, Amaoka K, Masubuchi Y, et al (2018) Overview of automotive structural composites technology developments in Japan. Compos Sci Technol 155:221-246. https://doi.org/10.1016/j.compscitech.2017.09.015

8. Arhant M, Davies P (2019) Thermoplastic matrix composites for marine applications. Elsevier Ltd.

9. Bañon F, Sambruno A, Batista M, et al (2020) Surface quality and free energy evaluation of s275 steel by shot blasting, abrasive water jet texturing and laser surface texturing. Metals (Basel) 10:. https://doi.org/10.3390/met10020290

10. Ahmad F, Manral A, Bajpai PK (2019) Machining of Thermoplastic Composites. In: Processing of Green Composites. Springer Singapore, pp 107-123

11. Voss R, Seeholzer L, Kuster F, Wegener K (2017) Influence of fibre orientation, tool geometry and process parameters on surface quality in milling of CFRP. CIRP J Manuf Sci Technol 18:75-91. https://doi.org/10.1016/j.cirpj.2016.10.002

12. Kerrigan K, O'Donnell GE (2016) On the Relationship between Cutting Temperature and Workpiece Polymer Degradation during CFRP Edge Trimming. Procedia CIRP 55:170-175. https://doi.org/10.1016/j.procir.2016.08.041 
13. Nor Khairusshima MK, Muhammad Hafiz Zakwan B, Suhaily M, et al (2018) The optimization study on the tool wear of carbide cutting tool during milling Carbon Fibre Reinforced (CFRP) using Response Surface Methodology (RSM). IOP Conf Ser Mater Sci Eng 290:. https://doi.org/10.1088/1757-899X/290/1/012068

14. Haddad M, Zitoune R, Eyma F, Castanie B (2014) Study of the surface defects and dust generated during trimming of CFRP: Influence of tool geometry, machining parameters and cutting speed range. Compos Part A Appl Sci Manuf 66:142-154. https://doi.org/10.1016/j.compositesa.2014.07.005

15. Wang GD, Melly SK, Li N, et al (2018) Research on milling strategies to reduce delamination damage during machining of holes in CFRP/Ti stack. Compos Struct 200:679-688. https://doi.org/10.1016/j.compstruct.2018.06.011

16. Wang G, Stephen Kirwa M, Li N (2018) Experimental studies on a two-step technique to reduce delamination damage during milling of large diameter holes in CFRP/Al stack. Compos Struct 188:330-339. https://doi.org/10.1016/j.compstruct.2018.01.039

17. Turki $Y$, Habak M, Velasco R, Vantomme $P$ (2017) Highlighting cutting mechanisms encountered in carbon/epoxy composite drilling using orthogonal cutting. Int J Adv Manuf Technol 92:685-697. https://doi.org/10.1007/s00170-017-0153-0

18. Masek P, Zeman P, Kolar P (2013) Development of a cutting tool for composites with thermoplastic matrix. Mod Mach Sci J October:423-427. https://doi.org/10.17973/MMSJ.2013

19. Xu J, Li C, Chen M, et al (2019) An investigation of drilling high-strength CFRP composites using specialized drills. Int J Adv Manuf Technol 103:3425-3442. https://doi.org/10.1007/s00170-01903753-8

20. Sui J, Wang C (2019) Machinability study of unidirectional CFRP laminates by slot milling. Int J Adv Manuf Technol 100:189-197. https://doi.org/10.1007/s00170-018-2730-2

21. Khairusshima MKN, Aqella AKN, Sharifah ISS (2017) Optimization of Milling Carbon Fibre Reinforced Plastic Using RSM. Procedia Eng 184:518-528. https://doi.org/10.1016/j.proeng.2017.04.122

22. Geier N, Pereszlai C (2020) Analysis of characteristics of surface roughness of Machined CFRP composites. Period Polytech Mech Eng 64:67-80. https://doi.org/10.3311/PPme.14436

23. Xu J, Huang X, Chen M, Paulo Davim J (2020) Drilling characteristics of carbon/epoxy and carbon/polyimide composites. Mater Manuf Process 00:1-9. https://doi.org/10.1080/10426914.2020.1784935

24. Xu J, Lin T, Chen M, Davim JP (2020) Machining responses of high-strength carbon/epoxy composites using diamond-coated brad spur drills. Mater Manuf Process December:1-8. https://doi.org/10.1080/10426914.2020.1854475

25. Xu J, Huang X, Davim JP, et al (2020) On the machining behavior of carbon fiber reinforced polyimide and PEEK thermoplastic composites. Polym Compos 41:3649-3663. https://doi.org/10.1002/pc.25663

26. Khanna N, Pusavec F, Agrawal C, Krolczyk GM (2020) Measurement and evaluation of hole attributes for drilling CFRP composites using an indigenously developed cryogenic machining facility. Meas $J$ 
Int Meas Confed 154:107504. https://doi.org/10.1016/j.measurement.2020.107504

27. Nguyen D, Abdullah MS Bin, Khawarizmi R, et al (2020) The effect of fiber orientation on tool wear in edge-trimming of carbon fiber reinforced plastics (CFRP) laminates. Wear 450-451:203213. https://doi.org/10.1016/j.wear.2020.203213

28. Ozkan D, Gok MS, Oge M, Karaoglanli AC (2019) Milling behavior analysis of Carbon FiberReinforced Polymer (CFRP) composites. Mater Today Proc 11:526-533. https://doi.org/10.1016/j.matpr.2019.01.024

29. Pereira RBD, Lauro CH, Brandão LC, et al (2019) Tool wear in dry helical milling for hole-making in AISI H13 hardened steel. Int J Adv Manuf Technol 101:2425-2439. https://doi.org/10.1007/s00170018-3129-9

30. Wang B, Chang K, Wang M, et al (2018) Experimental studies on helical milling process to improve hole quality for the Superalloy (MSRR7197). Int J Adv Manuf Technol 99:1449-1458. https://doi.org/10.1007/s00170-018-2588-3

31. El-Hofy M, Helmy MO, Escobar-Palafox G, et al (2018) Abrasive water jet machining of multidirectional CFRP laminates. Procedia CIRP 68:535-540. https://doi.org/10.1016/j.procir.2017.12.109

32. Hintze W, Cordes $M$, Koerkel G (2015) Influence of weave structure on delamination when milling CFRP. J Mater Process Technol 216:199-205. https://doi.org/10.1016/j.jmatprotec.2014.09.004

33. Shengchao H, Yan C, Jiuhua X, Jingwen Z (2014) Experimental Study of Tool Wear in Milling Multidirectional CFRP Laminates. Mater Sci Forum 770:276-280. https://doi.org/10.4028/www.scientific.net/MSF.770.276

34. Chen Y, Guo X, Zhang K, et al (2019) Study on the surface quality of CFRP machined by microtextured milling tools. J Manuf Process 37:114-123. https://doi.org/10.1016/j.jmapro.2018.11.021

35. Dhanawade A, Kumar S (2017) Experimental study of delamination and kerf geometry of carbon epoxy composite machined by abrasive water jet. J Compos Mater 51:3373-3390. https://doi.org/10.1177/0021998316688950

36. Pahuja R, Ramulu M, Hashish M (2019) Surface quality and kerf width prediction in abrasive water jet machining of metal-composite stacks. Compos Part B Eng 175:107134. https://doi.org/10.1016/j.compositesb.2019.107134

37. Fu R, Jia Z, Wang F, et al (2018) Drill-exit temperature characteristics in drilling of UD and MD CFRP composites based on infrared thermography. Int J Mach Tools Manuf 135:24-37. https://doi.org/10.1016/j.ijmachtools.2018.08.002

\section{Figures}




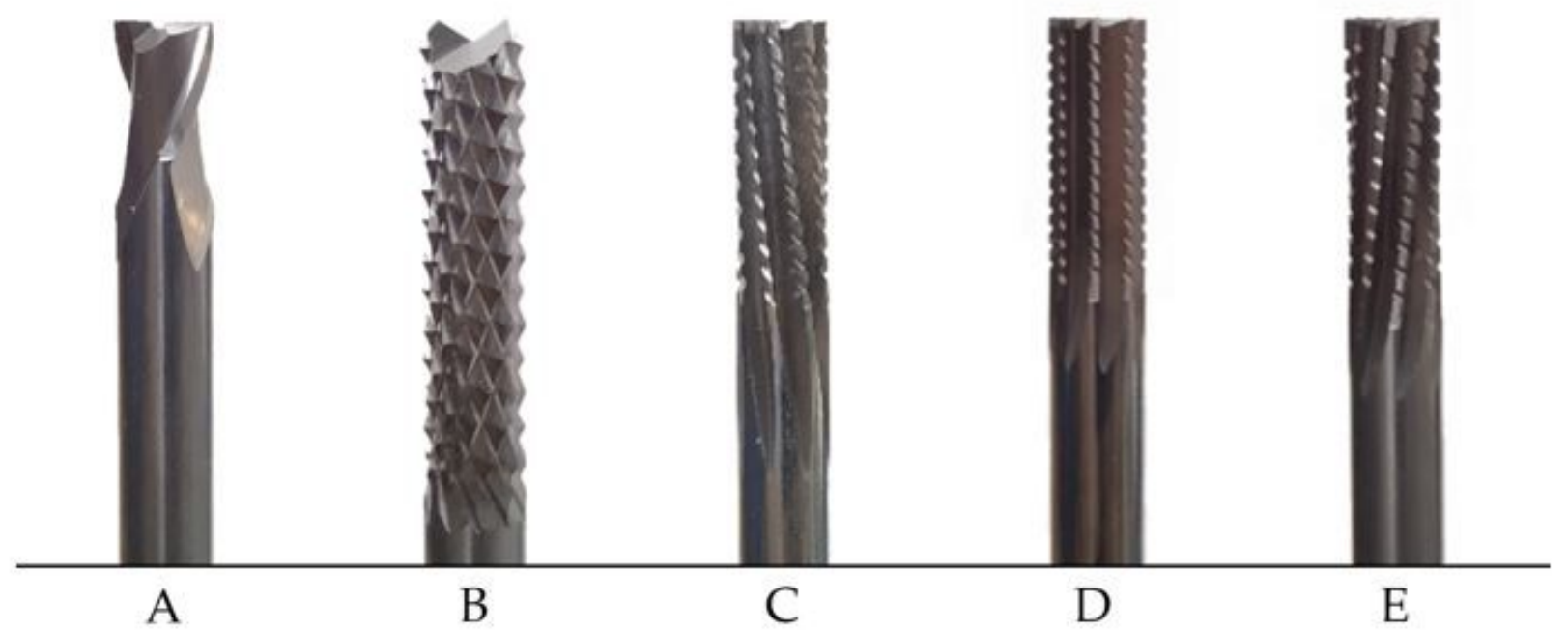

Figure 1

Image and designation of the tools employed in the experimental study.
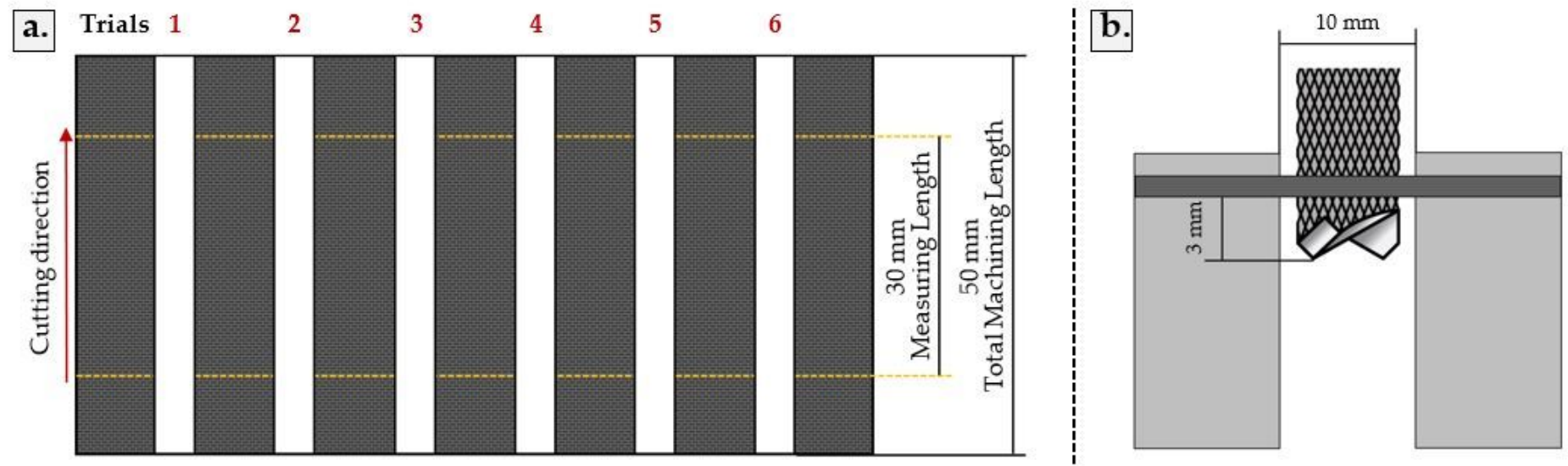

Figure 2

a. Machining layout on the composite; b. Tool positioning in machining. 

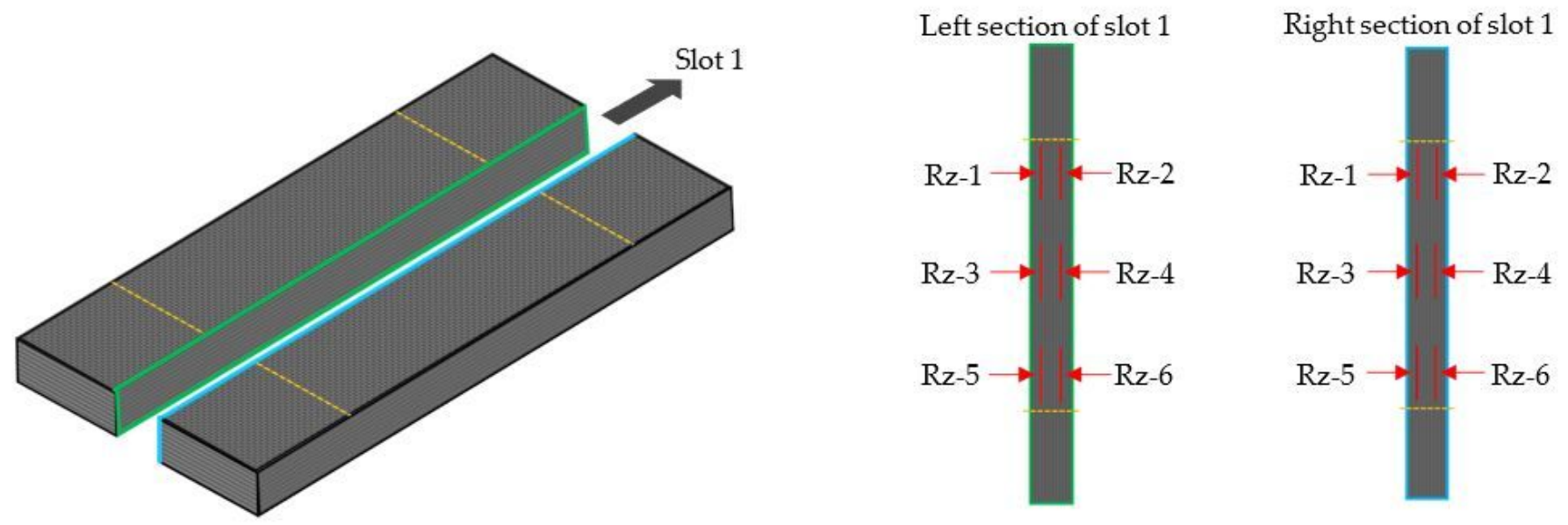

Figure 3

Setting of roughness parameter Rz measurements in the material section.

a. Up-milling
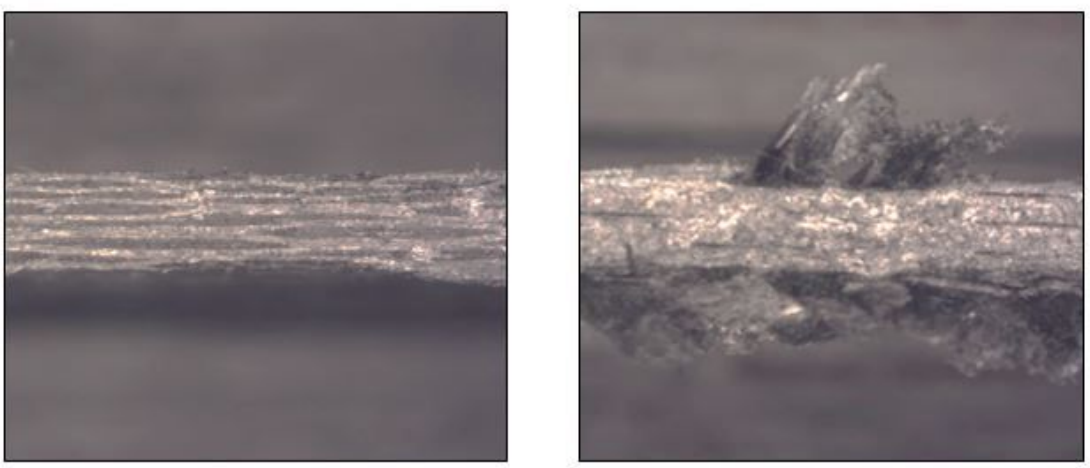

Down-milling
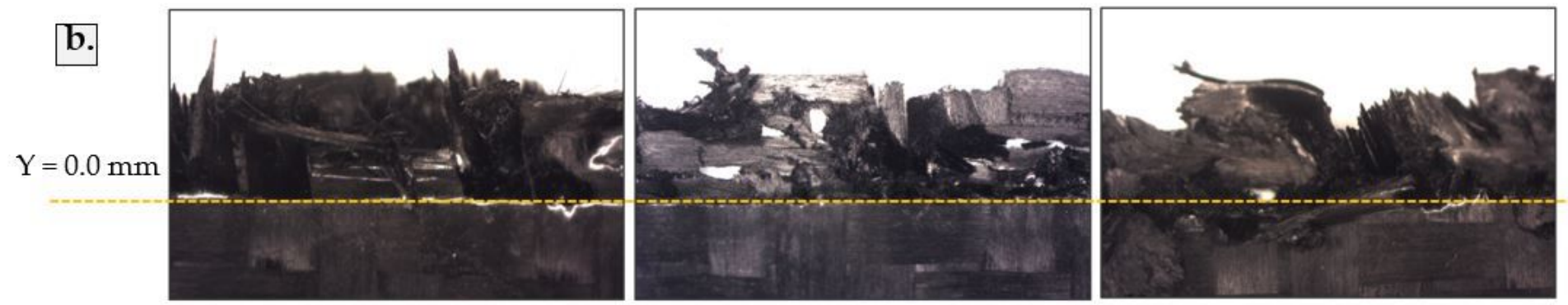

Figure 4

a. Visual inspection of a slot section: left up-milling, right down-milling; b. Fiber pull-out defect in down milling parts $(2 x)$. 


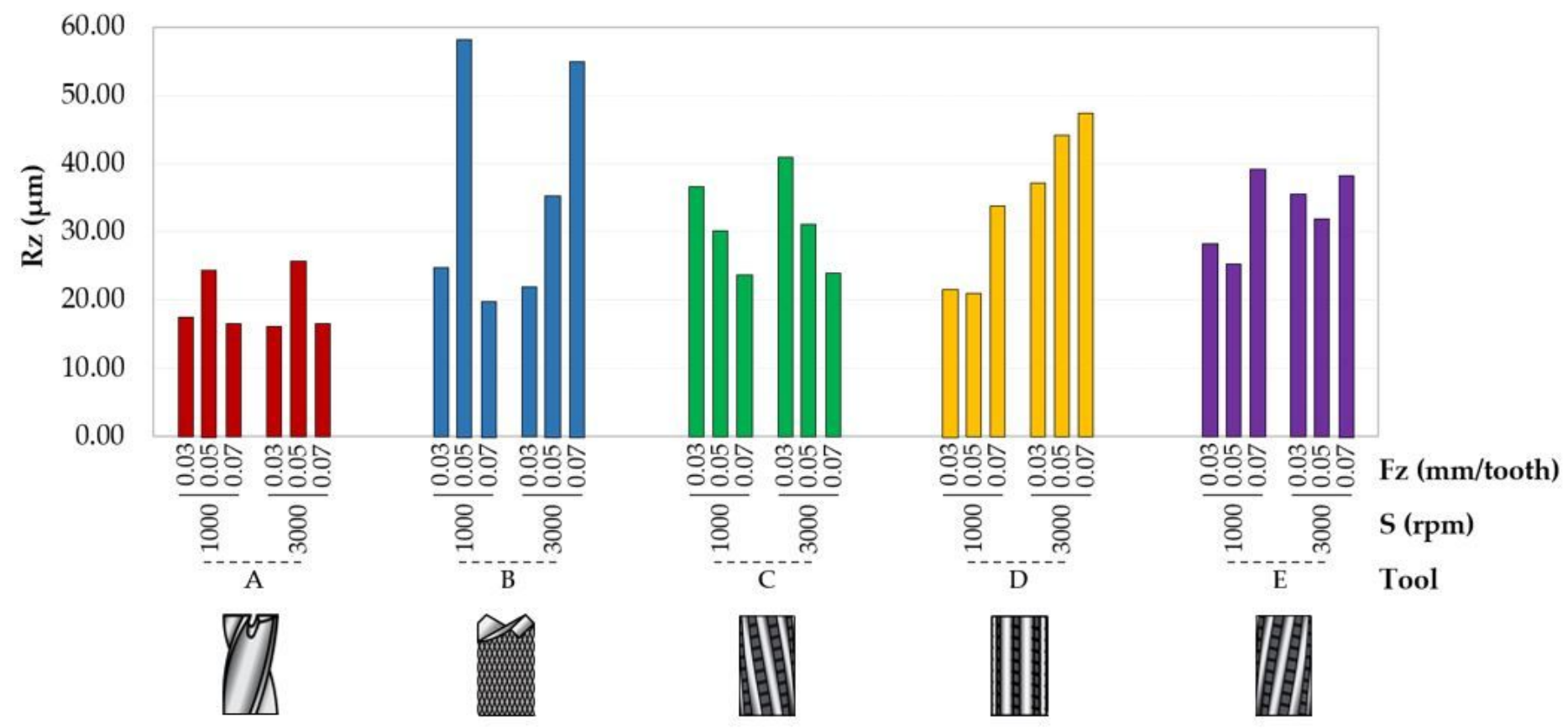

Figure 5

Graphical representation of Rz values achieved by each tool.
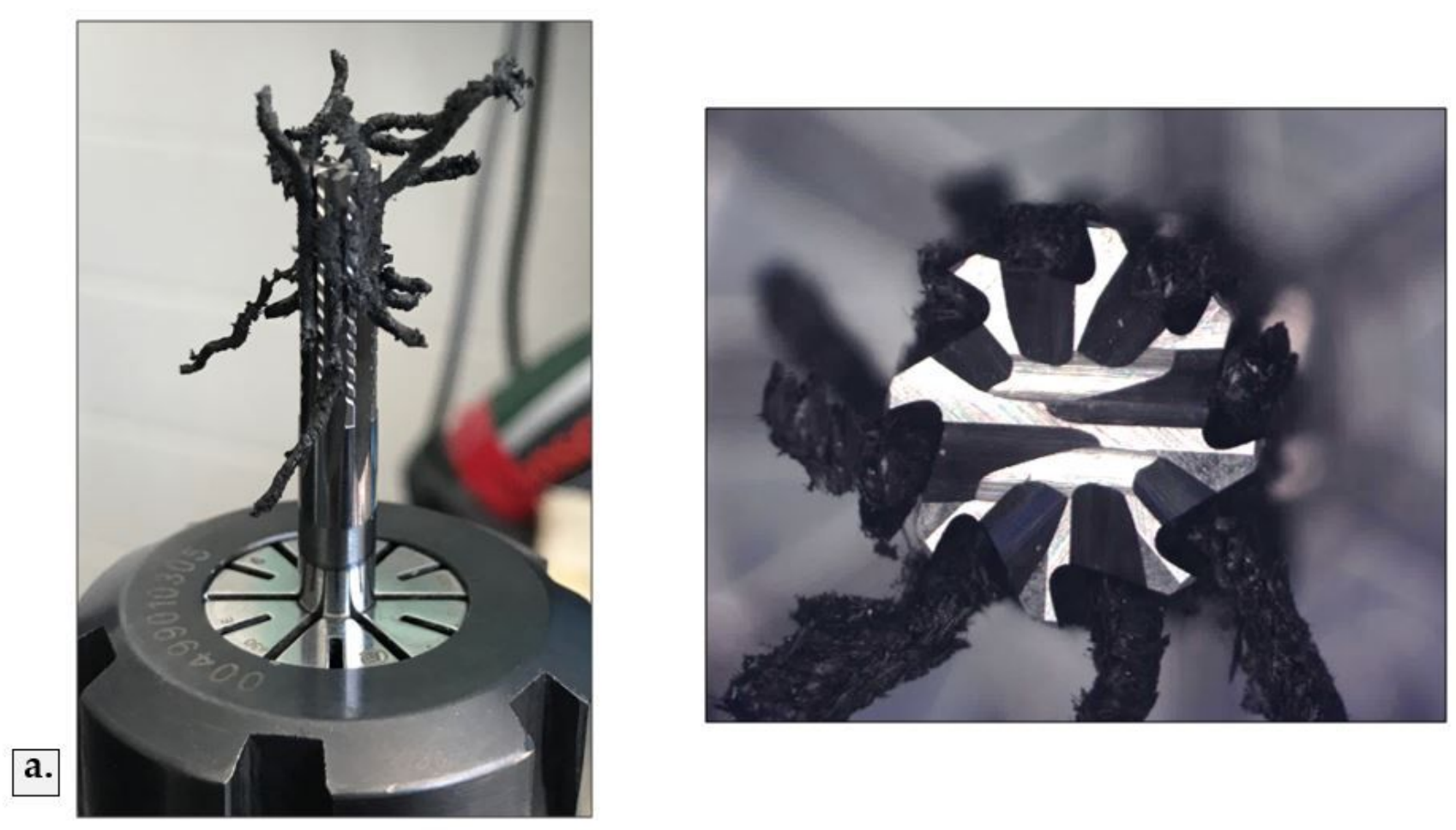

b.

Figure 6 
a. Carbon fiber particles consolidating with the composite matrix blocking the evacuation channels of tool D; b. Plan view of the stuck tool.

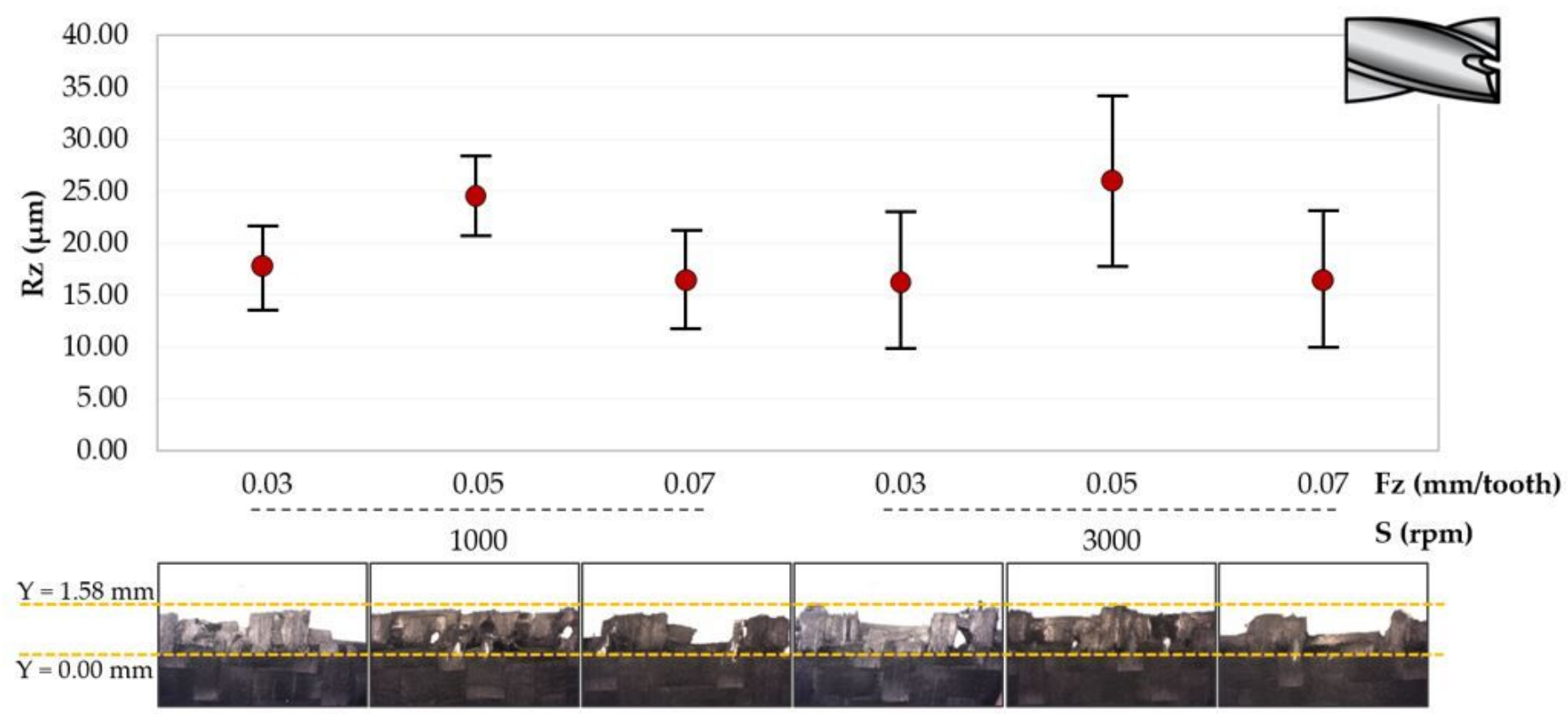

Figure 7

Graphical representation of average Rz values, their deviations and the fiber pull-out occasioned by tool A.

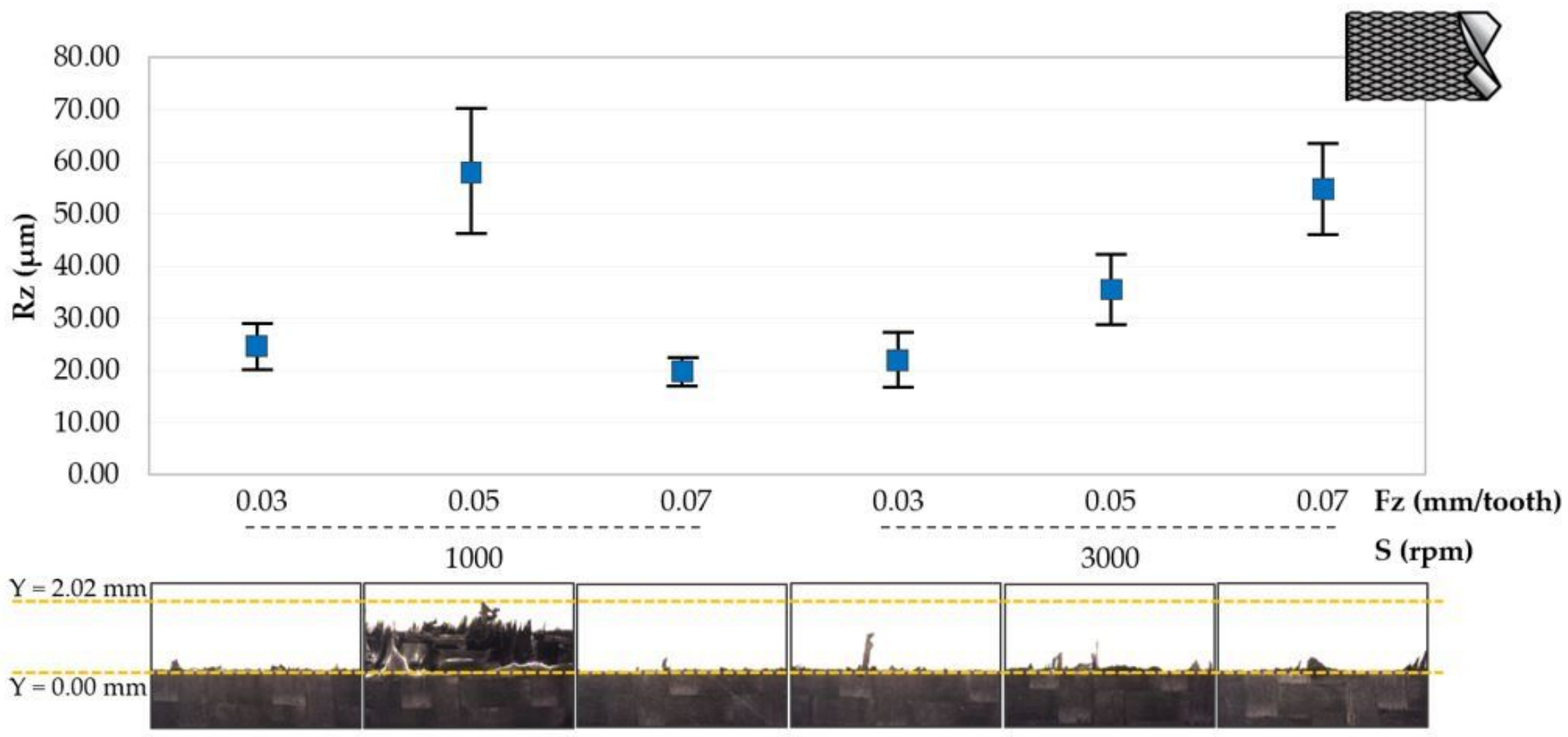

Figure 8 
Graphical representation of average Rz values, their deviations and the fiber pull-out occasioned by tool B.
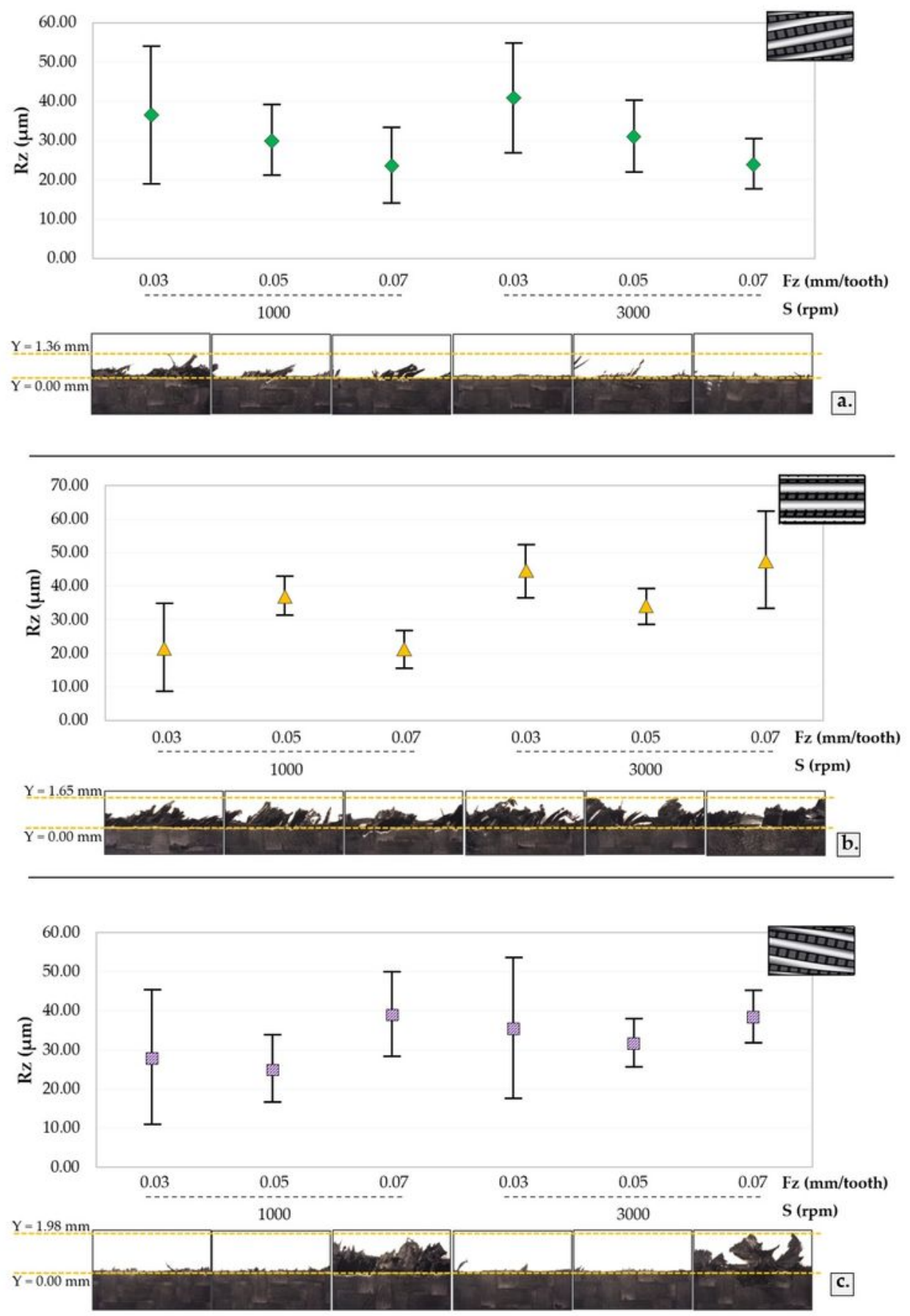

\section{Figure 9}

Graphical representation of average Rz values, their deviations and the fiber pull-out occasioned by: $a$. Tool C; b. Tool D; c. Tool E. 